\title{
Colaboração e supervisão na ADD: Estratégias formativas de desenvolvimento profissional dos professores
}

\section{Collaboration and Supervision on ADD: Formative strategies of teacher's professional development}

\author{
Luiz Queiroga*, Carlos Barreira**, Albertina Oliveira** \\ * Instituto Piaget, Viseu, ** Faculdade de Psicologia e Ciências da Educação, Coimbra
}

\begin{abstract}
Resumo
A Avaliação do Desempenho Docente (ADD) assenta os seus pressupostos na observação de aulas entre pares, pelo que importa conhecer até que ponto esta tem contribuído para a melhoria das práticas pedagógicas e para o desenvolvimento profissional dos professores. Optou-se por realizar um Estudo de Caso, recorrendo-se a uma abordagem mista, qualitativa e quantitativa. Os sujeitos participantes, num total de 108, são docentes de um Agrupamento de Escolas da Região Centro. A avaliação pelos pares internos parece ter envolvido os docentes no processo de observação de aulas, ao ponto de, ter ocorrido trabalho colaborativo e práticas reflexivas.

Palavras chave: avaliação do desempenho docente, observação de aulas, desenvolvimento profissional.
\end{abstract}

\begin{abstract}
The teacher appraisal rests its assumptions on the classroom observation between peers. Thus it is important to know how far this kind of observation has contributed for the development of the pedagogical practices and for teachers' professional development. For that purpose it was decided to follow a Case Study research, using a mixed qualitative and quantitative approach. The participating subjects, in a total of 108, are teachers of a Grouping of Centre Region Schools. The appraisal by the internal peers seems to have involved teachers on the process of classroom observation, leading to a collaborative work and reflective practices.
\end{abstract}

Key words: teacher appraisal, classroom observation, professional development.

A ADD surge como uma plataforma de formação de professores, onde a supervisão pelos pares desempenha um papel fundamental no desenvolvimento pessoal e profissional dos professores. A supervisão interpares ou supervisão horizontal (Alarcão \& Roldão, 2008) assume papel de relevo, tendo a auto-supervisão o seu lugar assegurado num processo colaborativo, cujo objetivo "não é apenas o desenvolvimento do conhecimento; visa também o desabrochar de capacidades e o repensar de atitudes" (Alarcão \& Tavares, 2003, p. 119). A sua orientação deve ser no sentido de permitir uma mudança das práticas dos professores e educadores, com a finalidade de possibilitar uma reestruturação da profissão, visando o aperfeiçoamento dos saberes, das técnicas e das atitudes necessárias ao desempenho. $\mathrm{O}$ foco da supervisão continua a ser o da sala de aula, sendo que Vieira e Moreira (2011, p. 11) referem que "no quadro da avaliação do desempenho a auto-supervisão pode representar a estratégia básica de autoavaliação e de desenvolvimento profissional do professor, independentemente da existência de formas de supervisão externa, embora estas possam contribuir para uma supervisão mais dialogada e crítica". Neste contexto, a supervisão desempenha um papel fulcral no processo de formação dos professores, tendo como principal função a de apoiar e regular o processo formativo (Alarcão \& Roldão, 2008), assumindo "um papel muito importante na melhoria do desempenho docente nas diferentes atividades exercidas pelos professores, especialmente no que se refere à prática letiva" (Casanova, 2011, p. 103).

O que é supervisão? Para Vieira (1993, p. 28) a supervisão no quadro de formação de professores é encarada "como uma atuação de monitorização sistemática da prática pedagógica, sobretudo através de procedimentos de reflexão e de experimentação". Por sua vez, Nolan e Hoover (2011) asseveram que a supervisão de professores tem uma função organizacional, que procura promover o desenvolvimento dos professores, para assim possibilitar uma melhoria do seu desempenho, bem como dos alunos. Por seu turno, Oliveira-Formosinho (2002, p. 5) argumenta que a supervisão é um "instrumento de formação, inovação e mudança, situando-se na escola como organização em processo de desenvolvimento e de re/qualificação".

Neste sentido, entende-se o facto de a supervisão assumir atualmente na avaliação do professor um papel preponderante, em virtude da ADD assentar no pressuposto de que "o aperfeiçoamento profissional dos professores contribui para a melhoria da escola e a melhoria da aprendizagem dos alunos" (Machado \& Formosinho, 2010, p. 110). Neste quadro, a supervisão clínica ganha semblante, pelo facto de ser aquela que, 
"no contexto da avaliação de desempenho, pode apoiar a observação de aulas e a reconstrução das práticas dos professores" (Vieira \& Moreira, 2011, p. 29). Os seus desígnios assentam nos princípios da colegialidade, em que o supervisor é visto como um colega que desenvolve uma relação de confiança com o professor supervisionado, com o objetivo de melhorar a sua prática e a aprendizagem do aluno (Nolan \& Hoover, 2011). Segundo Alarcão e Tavares (2003, pp. 25-26) a supervisão clínica é um modelo que "caracteriza-se pela colaboração entre professor e supervisor com vista ao aperfeiçoamento da prática docente com base na observação e análise das situações reais de ensino." O objetivo do modelo de supervisão clínica é melhorar a prática de ensino do docente, constituindo-se a sala de aula espaço privilegiado de observação e reflexão, e é pela "análise conjunta dos fenómenos ocorridos, feita pelo professor e pelo supervisor" (Alarcão \& Tavares, 2003, p. 24) que se opera a formação. O supervisor tem como função ajudar colaborativamente o professor em formação a melhorar o seu ensino, pelo que a supervisão clínica, segundo Glickman, Gordon e Ross-Gordon (2004), assume preponderância enquanto processo que potencia o desenvolvimento pessoal e profissional do docente. Logo, a supervisão clínica assenta sobre os propósitos da avaliação formativa, funcionando como um mecanismo de apoio colegial na aula, que faculta assistência direta ao professor, pelo que é este quem decide o enfoque da supervisão e os assuntos a serem discutidos. Portanto, o cerne da atividade da supervisão clínica está na colaboração existente entre supervisor e supervisionado, que vão refletir sobre os dados recolhidos durante a observação de uma aula, sendo um processo dinâmico de interação e introspeção.

Perante um cenário paritário e colegial, a supervisão tem que ser encarada como um "veículo" transformador, ideologicamente assente em pressupostos colaborativos entre os pares, baseando-se na peer (super) vision como um processo de reflexão conjunta que procura o desenvolvimento das competências científicas e pedagógicas do docente.

No panorama da ADD, a supervisão não deve ser equacionada como um propósito simplista avaliativo do professor, tendo como finalidade a mera atribuição de uma menção que permita ao avaliado progredir na carreira. Os seus intentos são muito mais nobres, numa conjuntura de regulação das práticas pedagógicas que, segundo Sá-Chaves (2000) deve ser encarada como um contexto propício e promotor de desenvolvimento profissional e pessoal dos elementos envolvidos.

\section{Método}

\section{Participantes}

No que se refere ao estudo piloto, a população alvo incluiu todos os professores do pré-escolar e do $1^{\circ}, 2^{\circ}$ e $3^{\circ}$ ciclos que lecionavam em sete agrupamentos de escolas públicas da zona centro do país. A amostra foi constituída por conveniência e abrangeu 305 professores, sendo 224 do sexo feminino e 81 do sexo masculino. Do total de inquiridos, 170 não tiveram observação de aulas, enquanto os restantes, 135, foram alvo de aulas observadas no ano letivo de 2010/2011.

Quanto ao estudo principal, o questionário foi aplicado aos professores que lecionavam no agrupamento de escolas XPTO. A amostra final ficou constituída por 108 professores, dos quais 12 pertencem ao departamento curricular do Pré-Escolar, 31 ao do $1^{\circ}$ Ciclo, 17 ao de Matemática e Ciências Experimentais, 9 ao de Ciências Sociais e Humanas, 14 ao de Educação Especial, 14 ao de Línguas e 11 ao departamento de Expressões. Destes, $58,2 \%$ não solicitaram observação de aulas, enquanto $47,2 \%$ acabaram por o fazer.

\section{Instrumento}

Metodologicamente, optámos por realizar um Estudo de Caso, num Agrupamento de Escolas da Região Centro, recorrendo-se a uma abordagem mista, qualitativa e quantitativa (Amado, 2013). Em termos quantitativos, foi desenvolvido de raiz um questionário, "Questionário de Opinião sobre Avaliação do Desempenho Docente" (QOADD), para avaliar as perceções dos professores sobre a ADD, a supervisão pedagógica e a relação da avaliação pelos pares e o desenvolvimento profissional. Do ponto de vista qualitativo, realizaram-se cinco entrevistas semiestruturadas e foi efetuada uma análise documental.

A análise documental surge como a técnica de partida a ser implementada na recolha dos dados. Efetuou-se pelo facto de se assumir a necessidade de obtenção de informação contextual que permitisse complementar a obtida pelo referencial teórico e normativo e ajudar na construção do questionário. Analisaram-se documentos escritos disponibilizados pelo agrupamento de escolas XPTO, tais como: atas das reuniões de pré-observação e pós-observação, reflexões críticas dos avaliadores e avaliados e relatórios de autoavaliação.

As entrevistas iniciais surgem pela necessidade de obtenção de informação sobre o decreto regulamentar $n$. $^{\circ}$ 26/2012, de 21 de fevereiro, em virtude de este dispositivo albergar um conjunto de novas deliberações, bem como incorporar no modelo, outros intervenientes, repartindo as competências processuais e organizacionais entre as escolas e os Centos de Formação de Associação de Escolas.

O Questionário de Opinião sobre Avaliação do Desempenho Docente - "QOADD" foi construído tendo por base os referenciais teórico-normativos, a análise documental, as entrevistas iniciais, e a nossa experiência pessoal, enquanto professor avaliado com observação de aulas. O "QOADD" contempla quatro dimensões: Avaliação do Desempenho Docente; Processo de Supervisão Pedagógica; Desenvolvimento Profissional dos Professores e Avaliação pelos Pares.

\section{Procedimentos}

No estudo piloto, contactaram-se as direções dos agrupamentos selecionados, para informar sobre os objetivos do estudo e solicitar as autorizações necessárias. De forma a abarcar o maior número possível de respondentes, considerou-se que a reunião de departamento seria o local ideal para o efeito. Antes do início da reunião do conselho pedagógico, 
contactaram-se os coordenadores de departamento. Aos que mostraram disponibilidade, entregaram-se os questionários e um termo de aceitação para participar na investigação, bem como um documento com informação sobre o âmbito da investigação.

Quanto ao estudo principal, e após o diretor do agrupamento mostrar disponibilidade para colaborar, contactaram-se os coordenadores de departamento, a fim de os informar do âmbito e dos objetivos da investigação e estipulou-se que a aplicação do QOADD seria efetuada antes do início da reunião de departamento. Antes das respostas ao questionário, os professores foram informados do âmbito e tema do estudo, bem como dos procedimentos a adotar caso aceitassem colaborar. As respostas demoraram entre 15 a 20 minutos.

Para verificar a fiabilidade do QOADD, efetuou-se a análise da consistência interna, através do método de Alfa de Cronbach (Pestana \& Gageiro, 2008). Quanto à validade, optou-se pela utilização da Análise Fatorial Exploratória (AFE), com uma extração dos factores pelo método das componentes principais e uma rotação Ortogonal Varimax com a normalização de Keiser-Meyer Olkin (KMO) (Pestana \& Gageiro, 2008). Efetuaram-se alguns refinamentos, tais como redução do número de itens e eliminação de categorias na primeira dimensão (Avaliação do Desempenho Docente). No fim, o QOADD ficou composto por 70 itens.

\section{Resultados}

Perante a panóplia de resultados obtidos, apresentam-se aqueles que entendemos que conseguem dar resposta à principal questão em estudo: Em que medida a avaliação pelos pares contribuiu para o desenvolvimento profissional dos professores? Tomaremos como referência, dois de vários objetivos definidos: Identificar o modelo de supervisão pedagógica adotado no agrupamento de escolas em estudo; Verificar se a avaliação pelos pares teve como principal objetivo a prestação de contas, ou se contribuiu para o desenvolvimento profissional dos professores.

Modelo de supervisão pedagógica adotado no agrupamento de escolas em estudo. Com base nos dados obtidos pelos questionários sobre a forma como ocorreu o processo de supervisão pedagógica no agrupamento de escolas XPTO, apurámos que a maioria dos professores avaliadores e avaliados com observação de aulas, referiram que para cada aula observada foi realizada uma reunião de pré-observação e outra de pós-observação. No entanto, pelos dados constantes nos quatro processos documentais dos professores avaliados com observação de aulas, constatámos que nem sempre isso aconteceu. Apesar de a ADD estar associada à observação de aulas, o que implica desde logo uma relação direta com o modelo de supervisão clínica (Vieira \& Moreira, 2011), verificámos que nem sempre o processo de observação de aulas assentou totalmente nas quatro fases do ciclo de supervisão de Alarcão e Tavares (2003), pelo facto de terem ocorrido aulas observadas onde não existiu um encontro pré-observação, e outras onde não se realizou o encontro de pós-observação.
Avaliação pelos pares: prestação de contas ou desenvolvimento profissional dos professores. Os dados do questionário no que concerne a uma importante hipótese ${ }^{1}$ em estudo, permitem constatar que os professores que desempenharam cargos apresentam atitudes significativamente mais favoráveis em relação ao desenvolvimento profissional $(p=0,039)$ e à $\operatorname{ADD}(p=$ $0,007)$ do que os professores que não desempenharam cargos.

Por outro lado, embora os dados provenientes do questionário, no que concerne à hipótese $3^{2}$, não confirmem a existência de diferenças significativas entre as atitudes dos professores avaliados com observação de aulas e sem observação de aulas, relativamente à importância da ADD para o desenvolvimento profissional, parecem ser os professores que solicitaram observação de aulas que apresentam atitudes mais favoráveis. Constatamos pelos resultados do questionário, sobre a forma como ocorreu o processo de supervisão pedagógica no agrupamento de escolas $X P T O$, que os professores do mesmo grupo disciplinar desenvolveram trabalho colaborativo para a preparação das aulas observadas.

\section{Discussão}

Verificámos que no ano letivo de 2010/2011 o modelo de supervisão pedagógica utilizado na avaliação pelos pares internos não contemplou na totalidade todas as fases do ciclo de supervisão. Como a avaliação de professores assenta na heteroavaliação observativa intra pares, recomenda-se que o processo de observação de aulas empregue sempre, de forma repetitiva cíclica, para cada aula formal observada, todas as fases do ciclo de supervisão, nomeadamente, encontro de pré-observação, observação, análise dos dados e encontro de pós-observação, o que nem sempre aconteceu. Pelo exposto, concluímos que o modelo de supervisão adotado no processo de observação de aulas pelo agrupamento de escolas XPTO possui características do modelo clínico, mas não foi utilizado na íntegra.

Aos docentes que desempenharam cargos nas escolas, fruto da posição de liderança que ocupam, foi-lhes solicitado, por um lado, uma participação direta na construção das políticas a serem incrementadas e, por outro lado, a mobilização dos professores sob a sua esfera de influência, para a consecução dos ideais educativos. Estão mais habituados a desenvolverem trabalho com os seus pares, em que as trocas de experiências e reflexões são essenciais, pelo que percecionam a importância para a escola, professores e alunos das ações interativas conjuntas. Concluímos que para professores que desempenharam cargos, a avaliação pelos pares possuiu valências formativas o que possibilitou uma sucessão de envolvimentos entre os pares no interior das escolas, desencadeando oportunidades de formação e desenvolvimento

\footnotetext{
Os professores que desempenharam cargos apresentam atitudes significativamente mais favoráveis em relação à $\mathrm{ADD}$, desenvolvimento profissional e avaliação pelos pares do que os professores que não desempenharam cargos

${ }^{2}$ Existem diferenças significativas entre as atitudes dos professores avaliados com observação de aulas e dos professores avaliados sem observação de aulas relativamente à importância da ADD para o desenvolvimento profissional
} 
profissional. Este grupo de docentes acaba por apreender que "o sistema de avaliação cria uma oportunidade de desenvolvimento profissional que pode contribuir significativamente para melhorar a vida pedagógica das escolas e a qualidade do serviço que prestam à sociedade em que se inserem" (Fernandes, 2008, p. 29).

No seio do corpo docente, as trocas de experiências e reflexões não são práticas habituais entre os professores, muito pelo facto de ainda não existir uma cultura colaborativa enraizada no interior das escolas. A ADD pelos pares internos mostrou precisamente outro cenário. Em sede de grupo disciplinar, os professores efetuaram reflexões e trabalho colaborativo para a preparação das aulas assistidas. Esta mudança na cultura instituída, imputada à avaliação pelos pares tendo por base a observação de aulas e a supervisão, deixa antever a colaboração entre os professores como um mecanismo relevante para a melhoria do ensino e da escola, num quadro de partilha na tomada de decisões, na troca de saberes e conhecimentos sobre assuntos profissionais de interesse, assumindo a reflexão com os pares um papel fundamental. Portanto, a avaliação pelos pares internos parece ter envolvido os docentes no processo de observação de aulas, ao ponto de, entre os pares ter ocorrido trabalho colaborativo e práticas reflexivas.

\section{Referências}

Alarcão, I., \& Roldão, M ${ }^{\mathrm{a}}$. (2008). Supervisão: Um contexto de desenvolvimento profissional dos professores. Mangualde: Edições Pedago.

Alarcão, I., \& Tavares, J. (2003). Supervisão da prática pedagógica: Uma perspetiva de desenvolvimento $e$ aprendizagem. Coimbra: Livraria Almedina.

Amado, J. (2013). Manual de investigação qualitativa em educação. Coimbra: Imprensa da Universidade de Coimbra.

Casanova, Ma . (2011). Desafios da avaliação do desempenho docente. $8^{\circ}$ Congresso Nacional de Administração Pública: Desafios e Soluções (pp. 97-111). Lisboa.

Fernandes, D. (2008). Avaliação do desempenho docente: Desafios, problemas e oportunidades. Lisboa: Texto Editores.

Glickman, C., Gordon, S., \& Ross-Gordon, J. (2004). Supervision and instructional leadershi: A developmental approach (6th ed.). Boston: Pearson Education.

Machado, J., \& Formosinho, J. (2010). Desempenho, mérito e desenvolvimento para uma avaliação mais profissional dos professores. In J. Formosinho, J. Machado, \& J. Oliveira-Formosinho (Org.), Formação, desempenho e avaliação de professores (pp. 97-118). Mangualde: Edições Pedago.

Nolan, J., \& Hoover, L. (2011). Teacher supervision and evaluation: Theory into practice. USA: Jossey-Bass.

Oliveira-Formosinho, J. (2002). A supervisão na formação de professores I: Da sala à escola. Porto: Porto Editora.

Pestana, Ma., \& Gageiro, J. (2008). Análise de dados para ciências sociais. A complementaridade do SPSS. Lisboa: Edições Sílabo.
Sá - Chaves, I. (2000). Formação, Conhecimento, Supervisão - Contributos na Área de Formação de Professores. Aveiro: Universidade de Aveiro.

Vieira, F. (1993). Supervisão: Uma prática reflexiva de formação de professores. Porto: Edições Asa.

Vieira, F., \& Moreira, Ma (2011). Supervisão e avaliação do desempenho docente. Para uma abordagem de orientação transformadora. Cadernos CCAP-1Ministério da Educação- Conselho científico para a avaliação de professores. 